\title{
Design of railway bridges considering life-cycle assessment
}

1 Vincent Thiebault MSC, MEng Division of Structural Design and Bridges, KTH Royal Institute of Technology, Stockholm, Sweden

2. Guangli Du MSC

PhD student, Division of Structural Design and Bridges, KTH Royal Institute of Technology, Stockholm, Sweden

\section{Raid Karoumi PhD}

Professor, Head of Division of Structural Design and Bridges, KTH Royal Institute of Technology, Stockholm, Sweden
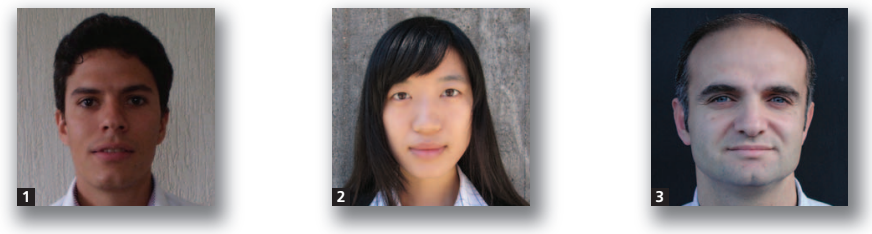

The world is currently confronted with the challenge of preventing environmental degradation and resource depletion. To compare the environmental performance of two railway bridge designs, an Excel-based model was developed with implementing a simplified quantitative life-cycle assessment. The model covers the entire life cycle of the bridge, from raw material extraction to construction materials recycling and disposal. Various assumptions are made for selecting the relevant emissions and environmental impacts. A streamlined approach is applied to compare the environmental burden throughout the life cycle of the Banafjäl Railway Bridge. The bridge is a simply supported composite structure carrying one railway track. Two track alternatives are investigated: ballasted track and fixed track. The results show that the environmental impacts of the fixed track alternative are lower than those of the ballasted track alternative. From a sustainable development perspective, it appears that fixed track has a significant advantage as the overall environmental impact is reduced by up to $77 \%$. The raw material phase is found to be decisive in the life cycle of both alternatives. The frequency of track replacement is identified as a key environmental parameter, because the extra environmental burden of traffic delay during bridge closure nearly overwhelmed the other life-cycle stages.

\section{Introduction}

The whole world is currently facing environmental problems resulting from natural resource depletion and energy consumption. The construction industry is still responsible for the largest share of global resources use and pollution emissions (Lorenz et al., 2008). Meanwhile, the increasing mass transportation demand throughout the EU requires the development of new infrastructures (European Commission, 2001). The decisions made now may have a long-term effect in environmental terms for the whole life cycle of a bridge. However, in present bridge project management, decisionmaking is primarily oriented towards the technique, safety and economic considerations, while the environmental impact is rarely taken into account or incorporated into the design process. As a result, life-cycle assessment (LCA), a 'cradle-to-grave' methodological framework for assessing the potential environmental impacts of a product over its entire life cycle, is increasingly used to provide environmental information regarding the extension of the existing infrastructure. From a life-cycle perspective, the environmental pressure of operating vehicles and the burden from the infrastructure, in particular bridges, as key links in the road and rail networks have indeed to be assessed (Chester and Horvath, 2009).

This paper presents a simplified quantitative LCA model that aims at comparing the environmental performance of two railway bridge designs. It provides environmental information to decision-makers when a decision is to be made regarding the bridge layout at an early stage in the design process. The tool is capable of assessing the life-cycle environmental burden of different railway bridge types, such as reinforced concrete beam bridges, trough bridges and steel-concrete composite girder bridges. 
The paper presents a case study related to the Banafjäl Bridge on the Bothnia line. This is a new high-speed railway line between Kramfors and Umeå in Sweden, opened to traffic in autumn 2010. The Banafjäl Bridge is a $7 \cdot 7 \mathrm{~m}$ wide composite bridge with a simply supported span of $42 \mathrm{~m}$. It carries a single ballasted track, with concrete sleepers and continuously welded UIC 60 rails (Botniabanan, 2010a). It has been partly redesigned (Gillet, 2010) to investigate another track system alternative; namely the fixed concrete track (i.e. a ballastless track alternative). The dimensions of the concrete slab were left unchanged, and only the design of the main beams was adjusted. According to the static design (Gillet, 2010), the fixed track system alternative would result in a saving of $15 \cdot 1 \%$ of steel.

The present study focuses on comparing the environmental performance of the Banafjäl Bridge, equipped with either a ballasted or a fixed track.

\section{System boundaries}

The model covers the entire life cycle of the bridge, from raw material extraction, through material production, material distribution, construction, maintenance until final material disposal, as presented in Figure 1. However, production of mine infrastructures and processing plants, machines and vehicles, processing of fossil fuels and production of electricity is excluded from the scope. In addition, processes and materials found to be insignificant in previous studies, such as formwork, ground preparation, bearings and expansion joints, are not considered in this study when comparing two alternative bridge solutions. By performing the LCA analysis, it is possible to compare alternative railway bridge solutions, in

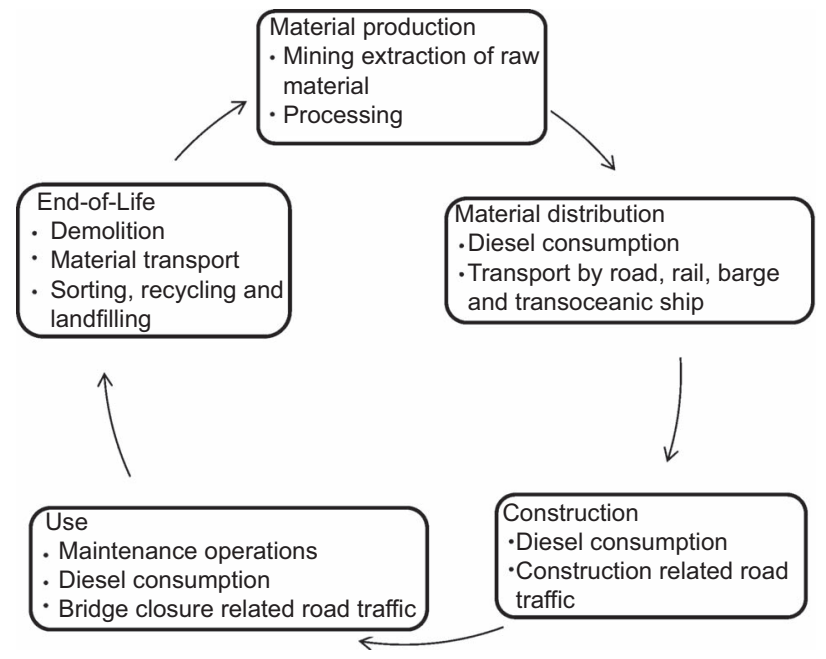

Figure 1. Bridge life-cycle phases considered the aspects of bridge structural types, material types and maintenance and waste management strategies.

The bridge components studied are the substructure and the superstructure, including the track system. Corresponding construction materials and energy are involved in the model, including steel, reinforcement steel, concrete for substructure and superstructure, zinc and steel protective coating (epoxypolyester paint).

In order to assess the extra environmental burden resulting from maintenance activities, several maintenance scenarios are modelled, for instance, the replacement of the bearings or expansion joints, re-painting of the steelwork and replacement of the whole bridge deck. These activities sometimes require the complete closure of the bridge to train traffic, resulting in a shift of the passenger and freight transport to the road.

For the end-of-life phase, different disposal scenarios are modelled for steel, namely direct recycling or disposal in landfills, while reinforced concrete is sorted, then partly recycled and sent to landfills.

The simplified approach focuses on a limited set of material and emission flows. Emissions to the air, namely carbon dioxide, carbon monoxide, methane, nitrogen oxides, sulfur dioxide, non-methane volatile organic compounds (NMVOCs) and particulate matter (PM10); emissions to the water, namely oils, biological oxygen demand (BOD), total suspended solid (TSS) and dissolved organic compounds (DOC); and generated solid wastes are taken into account. Impacts to the environment are then assessed for six impact categories, namely climate change, abiotic resource depletion, acidification, eutrophication, photo-oxidant formation and human toxicity.

\section{Model design and framework}

The LCA model is implemented in an Excel-based tool. It contains a number of spreadsheets that house user-inputs; materials, processes and emissions data; calculation factors and the calculation themselves; and the results are presented in the form of tables and graphs.

The material processing spreadsheets include the material flows and emissions for all processes involved in the manufacturing of concrete and steel, and involved in steel forming, welding, zinc coating and powder coating production. The thermal energy spreadsheet contains fuel consumption and emissions data related to fuel combustion. The transport spreadsheet provides fuel consumption and emissions data for all transportation modes (passenger cars, trucks, trains, barges and transoceanic ships). Finally, the material disposal spreadsheet houses data regarding reinforced concrete structure demolition and sorting. 
The material quantities input data chosen by the user are supported by rough estimations obtained from mathematical models presented in the Finnish Road Administration (Material quantity and cost estimation models for highway bridges, 2001, unpublished paper [in Finnish]), based on a survey of up to 500 road bridges designed between 1990 and 2003. These models provide the required material quantities for different types of bridge girders (concrete slab, pre-stressed concrete beam, concrete frame, concrete-steel composite beam) and substructure components (abutments and piers). These material quantity models were developed for road bridges, thus the results cannot be directly applied to railway bridges. Therefore, they are corrected with calibration factors, chosen by the user, to give the upper and lower bounds of the required material quantity for railway bridges.

At the life-cycle impact assessment step, the characterisation factors are retrieved from Guinée et al. (2001). A single total score for each bridge design alternative is then obtained by applying normalisation and weighting factors. The normalisation system used is the total emissions in western Europe in 1995. The weighting factors are those recommended by the US Environment Protection Agency. They are found in the software Building for Environmental and Economic Sustainability (BEES, 2009).

\section{Modelling of the life-cycle stages}

To assess the environmental impact over the life cycle of the bridge, a comprehensive model is established, including energy consumption, material manufacture, transportation, construction, maintenance and operation and end of life. Material flows and emissions data for each process and for each material were retrieved from the Swiss Centre for Life Cycle Inventories database (Ecoinvent, 2012). The specific elementary data corresponding to each material and process were progressively combined to obtain the aggregated material, energy and emission flows for the main bridge constituents. This inventory strategy was preferred to the direct use of aggregated data from the literature, because it provides fully transparent results - that is, the exact scope of the analysis is known; each inventory item allows data changes due to specific local conditions.

\subsection{Transport and thermal energy}

Diesel fuelled passenger cars, and two different truck loadcapacity categories have been chosen in the model. The first category houses trucks with weights ranging from $3.5 \mathrm{t}$ to $16 \mathrm{t}$, the second category houses trucks with weights exceeding $16 \mathrm{t}$. The average diesel fleet in 2010 has been considered for passenger cars. Passenger train traffic is assumed to be operated by high-speed trains. The electricity consumption and emissions relating to the operation of the German intercity express high-speed train is modelled. Average data for
Europe have been implemented for rail freight transportation and road transportation. The construction, operation and maintenance, and disposal of the transportation infrastructures are excluded from the model.

\subsection{Materials}

As presented in Table 1 and Table 2, the model includes two ready-mixed concrete types: a 'normal concrete' for the superstructure, and a concrete for the substructure that uses blast furnace slag cement. Blast furnace slag cement-based concrete is not used in Sweden, but for the sake of simplicity, it has been modelled to account for a high performance concrete type that does not require the addition of a plasticiser.

As presented in Table 3, two types of steel as described in Classen et al. (2009) are included in the model: unalloyed steel for the reinforcements, and low-alloyed steel for constructional steel; $63 \%$ of the steel is produced in basic oxygen furnaces and $37 \%$ in electric arc furnaces.

Materials as coatings for raw steel beams, ballast of railway track are also considered in the model. Raw steel beams are given their definitive shape by hot-rolling, then eventually are galvanised ('batch process') and welded on site by the metal active gas process. Afterwards, a coating material is applied to the steel beams: a mixture of epoxy and polyester resin has been modelled, with titanium dioxide as the pigment, thus resulting in a white powder. The ballast is modelled by the material of crushed gravel.

\subsection{Distribution}

The transportation of the concrete and steel products from the last processing plants in the supply chain to the construction site is included in the model. All types of concrete are assumed

\begin{tabular}{lcc}
\hline Pollutant & Normal concrete & $\begin{array}{c}\text { Concrete for sole } \\
\text { plate and foundation }\end{array}$ \\
\hline Carbon monoxide & 0.229 & 0.141 \\
Carbon dioxide & 265 & 155 \\
Methane & $3 \cdot 87 \times 10^{-3}$ & $2 \cdot 50 \times 10^{-3}$ \\
Nitrogen oxides & 0.689 & 0.449 \\
Sulfur dioxide & 0.109 & 0.0755 \\
NMVOCs & 0.0579 & 0.0367 \\
PM10 & 0.776 & 0.429 \\
Solid waste & $17 \cdot 2$ & 17.2 \\
& &
\end{tabular}

NMVOCs = methane volatile organic compounds; PM10 = particulate matter.

Table 1. Specific aggregated air emissions for the two concrete types $\left(\mathrm{kg} / \mathrm{m}^{3}\right)$ 


\begin{tabular}{lccccccccc} 
Type of concrete & Type & $\begin{array}{c}\text { Water } \\
\mathrm{kg} / \mathrm{m}^{3}\end{array}$ & w/C & $\begin{array}{c}\text { Density } \\
\mathrm{kg} / \mathrm{m}^{3}\end{array}$ & Cement type & $\mathrm{kg} / \mathrm{m}^{3}$ & $\begin{array}{c}\text { Aggregate } \\
\mathrm{kg} / \mathrm{m}^{3}\end{array}$ & $\begin{array}{c}\text { Type } \\
\text { Particle } \\
\text { size }\end{array}$ \\
\hline Normal concrete & C 20/25 & 186 & 0.62 & 2377 & CEM I 42.5 & 300 & 1891 & Round & $0 / 32$ \\
Concrete for sole plate & C 20/25 & $178 \cdot 8$ & 0.55 & 2387 & CEM III/B 32.5 & 325 & 1883 & Round & $0 / 32$
\end{tabular}

and foundation

Table 2. Composition of the different concrete types included in the model (Kellenberger et al., 2007)

to be provided by the same concrete plant. The structural and reinforcing steel are provided by the same mill. Four transportation modes are considered: namely truck, train, barge and transoceanic ship transportation.

Truck transportation is the most commonly used transportation mode. In this study, the truck load-capacity categories can be chosen as either $3 \cdot 5-16 \mathrm{t}$ or more than $16 \mathrm{t}$.

\subsection{Construction}

The construction phase accounts for the workers' transportation to and from the construction site and for the environmental impacts associated with the diesel consumption in the construction machines. The extra environmental burden of road traffic due to the longer construction time is considered. For example, if the first design alternative requires a construction duration of 90 days and the second alternative only 60 days, 30 days of road traffic instead of train traffic will be allocated to the first design alternative. The freight traffic is then operated by trucks with a weight exceeding $16 \mathrm{t}$, while the passenger traffic is operated by normal diesel cars.

\subsection{Use phase and maintenance operations}

The scheduled, periodic maintenance activities can efficiently prevent the bridge element from deterioration, therefore prolonging the service life and avoiding higher rehabilitation costs (Vieira and Horvath, 2008). However, significant environmental impact is caused by the maintenance activities. In this model, four maintenance and repair scenarios are assumed: repainting of the steelwork, replacement of the expansion joints and bearings, and eventually replacement of the entire bridge girder. The environmental burden relating to the extra material manufacturing and steel forming processes are computed for the repainting and girder replacement operations, while no material flows are considered for the replacement of the joints and bearings, because it has been decided to exclude them from the analysis. The diesel consumption by the construction machines is roughly evaluated with regard to the diesel demand at the construction stage, and calculated in proportion to the duration of the maintenance activities. When the maintenance activities require closing the bridge to traffic, the environmental impact resulting in the shift of passenger and freight transport from the rail to

\begin{tabular}{lccc}
\hline Pollutant & Unalloyed BOF steel & Low-alloyed BOF steel & Un- and low-alloyed EAF steel \\
\hline Carbon monoxide & $30 \cdot 8$ & $31 \cdot 1$ & $2 \cdot 67$ \\
Carbon dioxide & 1190 & 1460 & $80 \cdot 0$ \\
Methane & $4 \cdot 00 \times 10^{-3}$ & $0 \cdot 0261$ & $2 \cdot 39 \times 10^{-3}$ \\
Nitrogen oxides & $1 \cdot 15$ & $1 \cdot 96$ & $0 \cdot 562$ \\
Sulfur dioxide & $1 \cdot 89$ & $2 \cdot 99$ & $0 \cdot 0993$ \\
NMVOCs & $0 \cdot 168$ & $0 \cdot 265$ & $0 \cdot 0244$ \\
PM10 & $2 \cdot 20$ & $4 \cdot 07$ & $0 \cdot 365$ \\
Oils & $4 \cdot 27 \times 10^{-3}$ & $7 \cdot 04 \times 10^{-3}$ & $0 \cdot 00$ \\
TSS & $0 \cdot 00$ & $0 \cdot 266$ & $0 \cdot 00$ \\
BOD & $0 \cdot 0641$ & $0 \cdot 0641$ & $0 \cdot 00$ \\
DOC & $2 \cdot 32 \times 10^{-3}$ & $2 \cdot 32 \times 10^{-3}$ & $0 \cdot 00$ \\
Solid waste & 135 & 784 & 107 \\
\end{tabular}

$\mathrm{BOD}=$ biological oxygen demand; $\mathrm{BOF}=$ basic oxygen furnace; $\mathrm{DOC}=$ dissolved organic compounds; $\mathrm{EAF}=$ electric arc furnace; NMVOCs $=$ non-methane volatile organic compounds; TSS = total suspended solids.

Table 3. Specific aggregated emissions for un- and low-alloyed converter and electric steel $(\mathrm{kg} / \mathrm{t})$ 
the road is assessed. The bridge may be closed during the replacement of the expansion joints, bearings and entire girder.

The environmental burden of the production and application of steel paint coatings has been highlighted in Horvath and Hendrickson (1998) and Vieira and Horvath (2008). In an attempt to reduce both these impacts and the cost of the regular coating maintenance a dehumidification system is now often installed inside the steel box bridge deck, instead of painting the inner steel surface. This technology might become common practice in the future. The environmental burden due to the energy consumption of this dehumidification system was therefore included in the present model.

If the goal of the study requires taking into account the track system installed over the bridge, it might be of particular interest to include the environmental effects of the different maintenance of the tracks. However, due to lack of data regarding the energy consumption and emissions due to each operation, the environmental burden of the track maintenance operations has not been included in the model.

\subsection{End-of-life management}

During the LCA analysis process, the assumption of final endof-life scenarios will be made on the basis of actual project information. The end-of-life stage covers the process of bridge demolition, waste sorting, material reuse or recycling, final landfill and correlated transportation processes. In the present model, the end-of-life scenarios are assumed for the main material of constructional steel and reinforced concrete. The constructional steel can be either directly recycled, or disposed of in landfills. The percentage of constructional steel that is actually recycled is set by the user. The reinforced concrete is transported to a sorting plant, partly recycled and sent to landfills. The allocation rule regarding recycled materials complies with the Ecoinvent 2000 methodology described in Doka (2009).

When construction materials cannot be separated at the construction site, they are sent to a sorting plant. Recyclable and non-recyclable materials are split up and either recycled or disposed of in landfills. Regarding reinforced concrete, $60 \%$ of the mass is finally recycled, and $40 \%$ is disposed of in landfills (Doka, 2009). In the first approximation, all landfill materials are considered inert - that is, no environmental burden is associated with their storage. As for the direct recycling option, material recycling after sorting is excluded from the model.

Finally, construction material could be directly transported off to final disposal. The only burden associated with direct disposal in landfills is the transportation by trucks to the landfills, estimated at $15 \mathrm{~km}$ in Doka (2009).
The reinforced concrete structures are dismantled by tearing with hydraulic devices. The specific diesel consumption is calculated, based on the efficiency of this demolition mode and on the average fuel consumption of hydraulic devices. When a steel structure is to be dismantled, the diesel consumption for the demolition of the whole structure is assumed to be the same as that at the construction stage. The workers' transportation demand is assumed to be equal to that at the construction stage.

\section{Case study: goal and scope}

Ballasted tracks on bridges have many advantages over fixed tracks, such as lower construction costs, larger axle load distribution and high noise absorption. In Nyström and Prokopov (2010), investment costs to install $1 \mathrm{~m}$ of single ballasted track in Sweden are estimated at between SEK 3500 and SEK 4000, and between SEK 5000 and SEK 7000 for $1 \mathrm{~m}$ of single fixed track. However, ballasted tracks require more frequent maintenance operations than fixed tracks leading to more traffic disturbance and higher maintenance costs. The annual maintenance cost for a ballasted track is estimated to be more than six times higher than that for a fixed track (Nyström and Prokopov, 2010). The wear of the ballast, by abrasion and fragmentation, results in an expected service life of approximately 30 years for the ballasted track system, while the fixed track systems offer service lives of up to 60 years according to Botniabanan (2010a). In addition, ballast is relatively heavy, thus leading to higher costs due to both increased material and transportation needs for the construction of bridges.

The goal of carrying out LCA analysis is to compare the environmental performance of a case study bridge (the Banafjäl Bridge) equipped with either a conventional ballasted track system or a fixed track system. This will hopefully provide a reference base for the decision-makers to choose the most appropriate track solution from the environmental perspective.

The functional unit is the superstructure of the Banafjäl Bridge, over its entire expected service life of 60 years (Botniabanan, 2010b). In Gillet (2010), the re-designing of the substructure of the bridge equipped with a fixed track is not undertaken; the abutments are thus the same for the two alternatives.

The identical process for both alternatives - for example, rail manufacturing and workers' transportation, are not considered in the model. The fasteners and the anchor systems are excluded due to lack of data regarding their total steel mass. An important limitation is that the transport of ballast from the quarry to the bridge, which can have a significant impact on the environment according to Svensson (2006), is not considered due to a lack of data. 


\section{System definition}

The Banafjäl Bridge is a $7.7 \mathrm{~m}$ wide steel-concrete composite I girder bridge with a single simply supported span of $42 \mathrm{~m}$, as presented in Figure 2. The bridge, opened to traffic in 2010, carries a single ballasted track, with concrete sleepers and continuously welded UIC 60 rails (Botniabanan, 2010a).

In the case of the conventional ballasted track, the ballast bed has a density of $2039 \mathrm{~kg} / \mathrm{m}^{3}$ (Björklund, 2005), the concrete sleepers made of 'normal concrete' weigh approximately $300 \mathrm{~kg}$ and are placed every $600 \mathrm{~mm}$ (Botniabanan, 2010a), thus leading to an additional plain concrete volume per unit bridge length of $0.227 \mathrm{~m}^{3}$. In the case of the fixed track, the system installed over the New Årsta Bridge spanning Årstaviken in the south of Stockholm, is considered, as showed in Figure 3. Each rail lies on a trapezoidal $530 \mathrm{~mm}$ wide and $121 \mathrm{~mm}$ high concrete slab. An extra concrete layer of approximately $40 \mathrm{~mm}$ covers the bridge deck. The additional reinforced concrete volume per unit bridge length is thus $0 \cdot 394 \mathrm{~m}^{3}$ for a $7 \cdot 7 \mathrm{~m}$ wide bridge.

In a first approximation, the amount of rebar steel in the reinforced concrete is estimated at $3 \%$ of the plain concrete mass. Both alternatives use the UIC 60 rail type, with a linear mass of $60 \mathrm{~kg} / \mathrm{m}$ (Botniabanan, 2010a) and an expected service life of 30 years (Svensson, 2006).

Without specific data, the construction phase of the bridge is assumed to be identical for both alternatives - that is, the same diesel consumption and the same duration. The diesel consumption is taken to be equal to 6101 , which corresponds to the quantity of diesel burned in construction machines for the construction of the Klenevågen Bridge on Rv570 outside Bergen, Norway, a steel box girder bridge in one span of $42.8 \mathrm{~m}$ (Brattebø et al., 2009). The two I-beams require
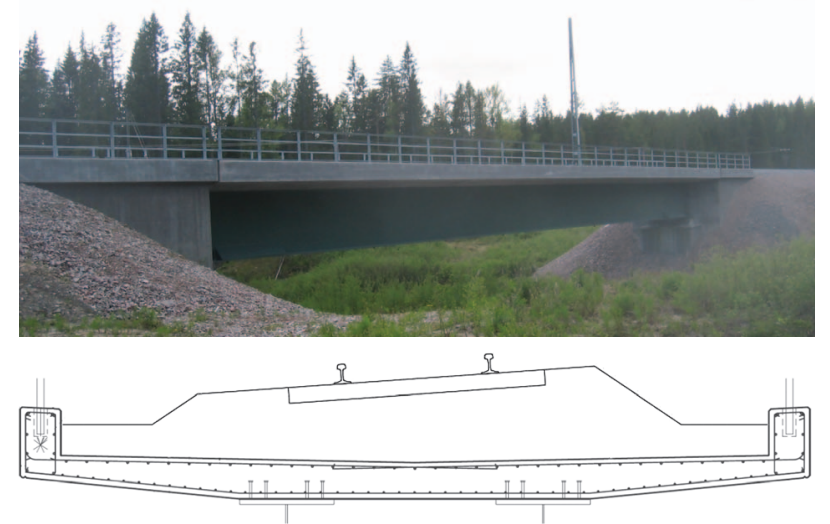

Figure 2. Banafjäl Bridge's concrete slab cross-section and ballast profile (Gillet, 2010; Lundmark, 2001)

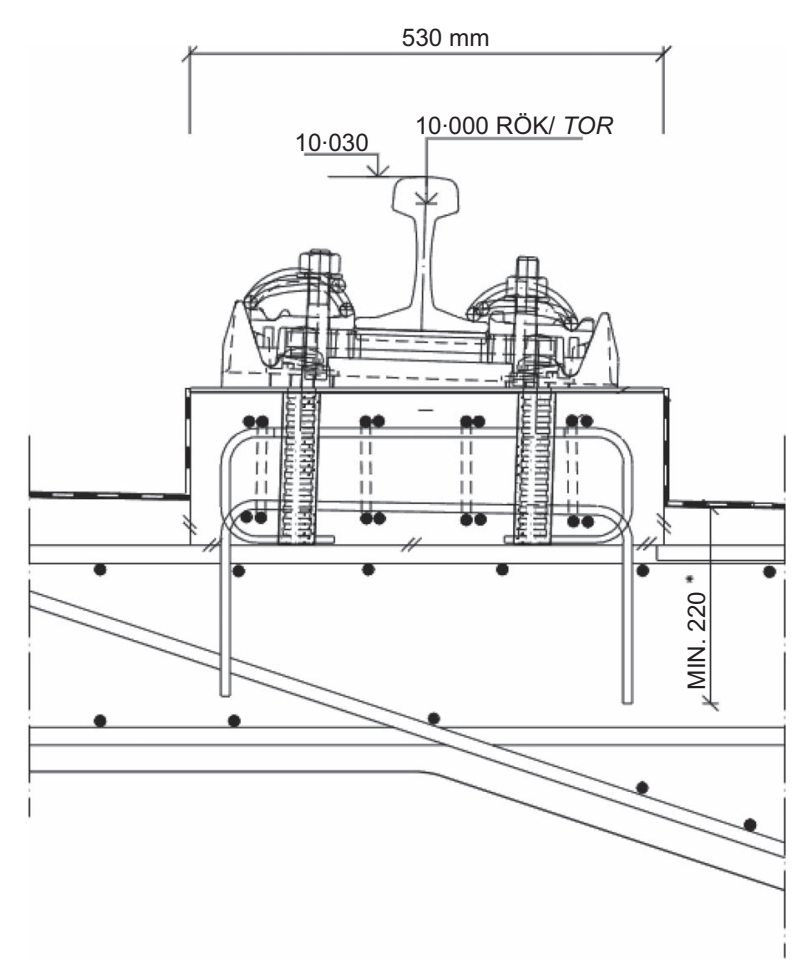

Figure 3. Cross-section of the rail and anchoring system on the New Årsta Bridge (Banverket, 2000)

approximately $8 \mathrm{~m}$ of welded joint per unit bridge length. The equipment and energy requirement to construct the ballasted and fixed track for the $42 \mathrm{~m}$ long Banafjäl Bridge is derived directly from Lee et al. (2008). In a first approximation, diesel combustion is used as surrogate data for gasoline. The total fuel consumption to build $42 \mathrm{~m}$ of ballasted and fixed track is 5631 and 62 1, respectively: fixed track construction consumes $89 \%$ less energy than ballasted track.

During the use phase, only the maintenance of the steel coating is considered, because the replacement of the expansion joints and bearings does not depend on the track system choice. The maintenance of the ballast profile and the track repairing activities are excluded from the analysis, as insufficient environmental data have been found regarding track maintenance activities. The conventional ballasted track needs to be replaced after 30 years of service, while the fixed track system is considered maintenance free during the 60-year lifespan of the bridge. Table 4 presents the input data for the ballasted and fixed track systems, per metre of track, through the life cycle.

The Banafjäl Bridge is a single track bridge, which means that the traffic is completely closed on the line during the replacement and maintenance of the track and the ballast. The passenger and freight traffic is then shifted to the road 


\begin{tabular}{llcccc} 
& Unit & $\begin{array}{c}\text { Ballasted track } \\
\text { system }\end{array}$ & $\begin{array}{c}\text { Ballasted track } \\
\text { system - life cycle }\end{array}$ & $\begin{array}{c}\text { Fixed track } \\
\text { system }\end{array}$ & $\begin{array}{c}\text { Fixed track } \\
\text { system - life cycle }\end{array}$ \\
\hline Plain concrete & $\mathrm{m}^{3} / \mathrm{m}$ & $2 \cdot 537$ & $2 \cdot 764$ & $2 \cdot 704$ & $2 \cdot 704$ \\
Rebar steel & $\mathrm{kg} / \mathrm{m}$ & $152 \cdot 4$ & $152 \cdot 4$ & $178 \cdot 4$ & $178 \cdot 4$ \\
Structural steel & $\mathrm{t} / \mathrm{m}$ & $2 \cdot 138$ & $2 \cdot 258$ & $1 \cdot 815$ & 1.935 \\
Galvanised area & $\mathrm{m} / \mathrm{m}$ & 1.96 & 1.96 & $1 \cdot 9$ & $1 \cdot 9$ \\
Epoxy-polyester coated area & $\mathrm{m} / \mathrm{m}$ & 1.96 & 1.96 & 1.9 & 1.9 \\
Ballast & $\mathrm{t} / \mathrm{m}$ & $8 \cdot 441$ & $16 \cdot 882$ & 0 & 0 \\
Diesel & litres & 1173 & 1736 & 672 & 672
\end{tabular}

Table 4. Input data for the ballasted and fixed track systems (per meter track)

during the bridge closure, estimated at 2 days. According to Botniabanan (2010c), the forecasted traffic for the Bothnia line in 2020 is 343800000 persons $/ \mathrm{km}$ for the passenger transport and $506400000 \mathrm{t} / \mathrm{km}$ for the freight transport. The model does not account for traffic growth.

It is assumed that at the end of life of the bridge, $100 \%$ of the structural steel is recycled, while all the concrete is sent to a sorting plant. No environmental burden is associated with the rails, because they are re-used at the end of the service life of the bridge.

Finally, similar assumptions regarding materials transport from the manufacturing plants to the construction site as for the Klenevågen Bridge in Brattebø et al. (2009), a steelconcrete composite box girder bridge, have been made.

\section{Inventory}

This section presents the results of the life-cycle inventory, in terms of material and energy use and emissions.

In the ballasted case, the energy used at the use phase dominates the total life-cycle energy consumption, followed by the material manufacturing-related energy as presented in Figure 4. The energy consumption at the use phase is very largely dominated by the road traffic-related energy use - that is, the extra energy consumed by the car and truck traffic when the bridge is closed for track and ballast replacement. In the case of the fixed track, the material production stage is dominant, while the use phase is insignificant.

The energy required to manufacture the construction materials is approximately $13 \%$ lower in the ballastless case than that in the ballasted case. This means that the extra concrete and rebar steel demand in the fixed track case $(6 \cdot 6 \%$ and $17 \cdot 1 \%$, respectively) does not compensate the lower structural steel demand of $14 \cdot 3 \%$. The distribution energy is $10 \%$ lower for the fixed track case than that for the ballasted alternative. The construction operations are insignificant in both cases regarding energy consumption. The end-of-life stage for the ballasted and fixed track case represents, respectively, $0 \cdot 8 \%$ and $2 \cdot 1 \%$ of the total life cycle energy demand. From a life-cycle perspective, the ballasted track alternative requires $77 \%$ more energy than the competing fixed track alternative.

The consumption of all raw materials throughout the life cycle of the bridge and the track systems is lower when the bridge is designed for a fixed track than for a ballasted track, as shown in Table 5. The major savings occur for the water (40\%), gravel $(78 \%)$ and refined oil products $(97 \%)$, because the production of ballast requires large quantities of these materials and because of the large diesel consumption during bridge closure. The replacement of the concrete sleepers compensate largely the extra consumption of concrete of $6.6 \%$ due to the installation of a fixed track, because the savings of sand, clay and bauxite at the end of the service life of the bridge reach $2.2 \% ; 3 \%$ of zinc is saved due to the decrease in the galvanised

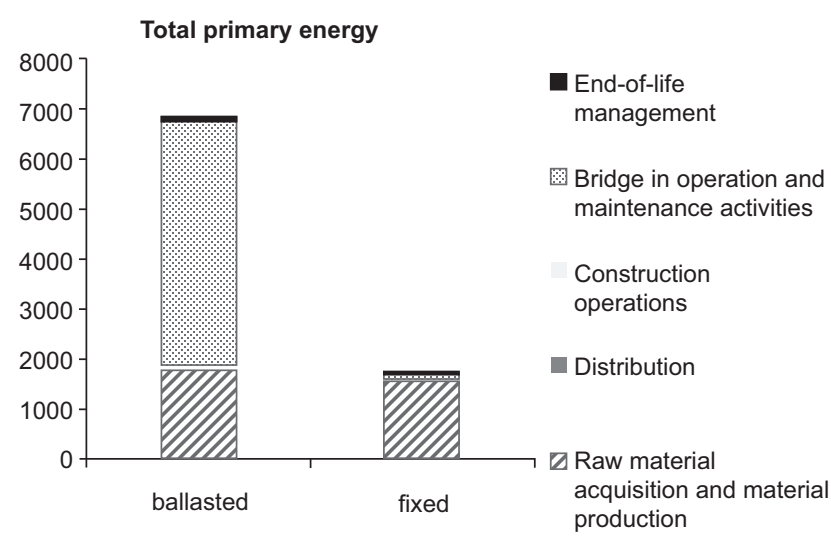

Figure 4. Total life cycle primary energy use (MJ) for the ballasted and fixed track alternatives 


\begin{tabular}{lcrrr} 
Raw material & Unit & Ballasted track system & Fixed track system & $\ldots . \Delta$ \\
\hline Water & $\mathrm{m}^{3}$ & 2813 & 1678 & -40 \\
Limestone & $\mathrm{kg}$ & 715008 & 693740 & -3 \\
Gravel & $\mathrm{kg}$ & 956856 & 214644 & -78 \\
Sand & $\mathrm{kg}$ & 291 & 285 & $-2 \cdot 2$ \\
Clay & $\mathrm{kg}$ & 14073 & 13768 & $-2 \cdot 2$ \\
Bauxite & $\mathrm{kg}$ & $1 \cdot 06$ & $1 \cdot 04$ & $-2 \cdot 2$ \\
Bentonite & $\mathrm{kg}$ & 1424 & 239 & -13 \\
Iron & $\mathrm{kg}$ & 22010 & 19299 & -12 \\
Dolomite & $\mathrm{kg}$ & 175 & 154 & -12 \\
Zinc & $\mathrm{kg}$ & 86 & 84 & -3 \\
Nickel & $\mathrm{kg}$ & 2714 & 1533 & $-14 \cdot 0$ \\
Chromium & 1810 & 1119 & $-14 \cdot 3$ \\
Manganese & 1306 & 20 & $-14 \cdot 3$ \\
Molybdenite & $\mathrm{kg}$ & 24 & 135 & $-14 \cdot 3$ \\
Niobium & $\mathrm{kg}$ & 158 & 64 & $-14 \cdot 3$ \\
Tungsten & $\mathrm{kg}$ & 74 & 121 & $-14 \cdot 3$ \\
Vanadium & $\mathrm{kg}$ & 141 & 32946 & $-14 \cdot 3$ \\
Coal products & $\mathrm{kg}$ & 37534 & 4024 & -12 \\
Refined oil products & $\mathrm{kg}$ & 139265 & 5756 & -97 \\
Natural gas & $\mathrm{kg}$ & 6576 & -12
\end{tabular}

Table 5. Raw materials use throughout the life cycle of the bridge equipped with a ballasted or a fixed track system

area. Finally, the saving of $14 \cdot 3 \%$ of steel alloys is made possible by choosing the fixed track system.

Figure 5 compares the emissions of carbon monoxide, carbon dioxide, nitrogen oxides, sulfur dioxide, NMVOCs and PM10 throughout the life cycle of the two competing alternatives: the fixed option yields fewer emissions to the air than the ballasted track option: carbon monoxide $(-29 \%)$, carbon dioxide
$(-76 \%)$, nitrogen oxides $(-90 \%)$, sulfur dioxide $(-18 \%)$, NMVOCs $(-48 \%)$ and PM10 $(-5 \%)$.

In the ballasted case, the raw materials acquisition and material production dominates the emissions of carbon monoxide (73\%), sulfur dioxide (88\%) and PM10 (93\%). The construction phase represents $6.5 \%$ of the total NMVOC emissions, and is of minor importance regarding the other
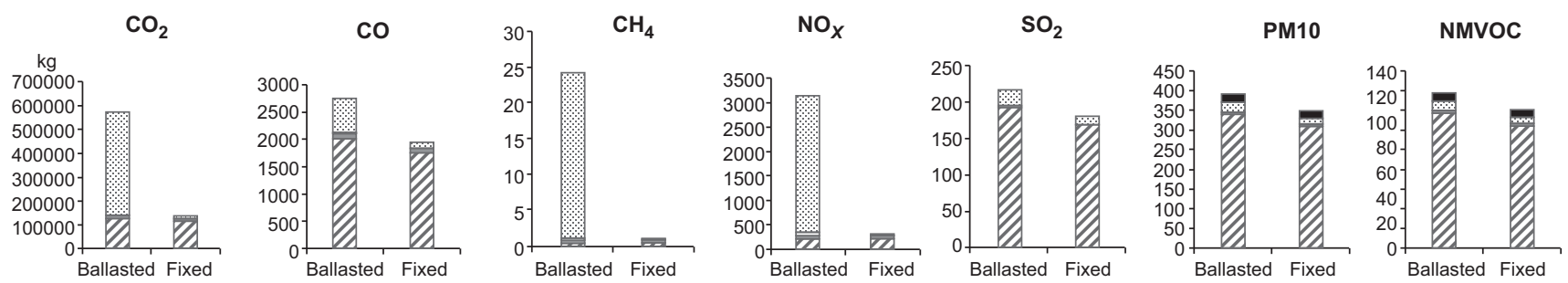

Z Raw material acquisition and material production

$\square$ Distribution

$\square$ Construction operations

$\square$ Bridge in operation and maintenance activities

End-of-life management

Figure 5. Life-cycle emissions to the air for both ballasted and fixed track alternatives (in kilograms). $\mathrm{CH}_{4}=$ methane; $\mathrm{CO}=$ carbon monoxide; $\mathrm{CO}_{2}=$ carbon dioxide; $\mathrm{NO}_{x}=$ nitrogen oxides; $\mathrm{PM} 10=$ particulate matter; $\mathrm{SO}_{2}=$ sulfur dioxide 
pollutant substances. The maintenance stage dominates the emissions of carbon dioxide (75\%), nitrogen oxides $(89 \%)$ and NMVOCs $(40 \%)$ emitted mainly by the road traffic, which results in the closure of the bridge while replacing the track. The end-of-life phase is of particular interest regarding the emissions of PM10, representing $5 \cdot 6 \%$ of the total life-cycle PM10 emissions, due to the large quantities emitted when dismantling the concrete structures. Finally, the transport of materials yields significant quantities of carbon monoxide, carbon dioxide, nitrogen oxides and NMVOCs.

In the fixed track case, the raw material acquisition and material production phase dominates the emissions of all air pollutants, followed by the distribution phase. The construction stage accounts for $4.9 \%$ of the total life-cycle emissions of NMVOCs, but is insignificant regarding the other air pollutants. In contrast to the ballasted case, the maintenance stage is of secondary importance.

Figure 6 compares the water releases for the two competing alternatives, expressed as oils, TSS, BOD, DOC and solid waste, throughout the life cycle the fixed track equipped Banafjäl Bridge yields fewer releases to the water than its competing counterpart: oils $(-18 \%)$, TSS $(-19 \%)$, BOD $(-17 \%)$ and DOC $(-18 \%)$. All releases to the water are strongly dominated by the raw material extraction and material production phase, followed by the maintenance phase in the case of the ballasted track alternative. The other phases are insignificant regarding water releases, like the construction phase, or do not lead to any releases to the water.
Finally, the conventional ballasted choice leads to an increase of $18 \%$ in the generation of solid waste in comparison with the fixed track choice. Once again, the raw material extraction and material production phase is clearly dominating the total waste production for the ballasted and fixed alternatives, in a proportion of $95 \%$ and $99 \cdot 8 \%$, respectively.

\section{Impact assessment}

The environmental performance of the fixed track design represents significant advantages in terms of all impact categories. The overall impact on the environment of the fixed alternative is $23 \%$ of that of the ballasted track alternative: the Banafjäl Bridge equipped with a fixed track system affects climate change and abiotic resources depletion up to $77 \%$ less, acidification $80 \%$ less, eutrophication $90 \%$ less and the formation of photo-oxidant 32\% less, as presented in Figure 7.

The most significant impacts are the depletion of natural resources, such as fossil fuels and steel alloys and global warming. The formation of photo-oxidant, acidification and eutrophication are of minor importance, but are not negligible. The impact on human health (human toxicity) with regard to the overall impact is found to be insignificant.

\section{Sensitivity analysis}

For bridges with a long lifespan, several assumptions are made when performing the LCA analysis, regarding life-cycle inventory data and operation processes. In order to use this simplified quantitative LCA as a decision-making tool, the
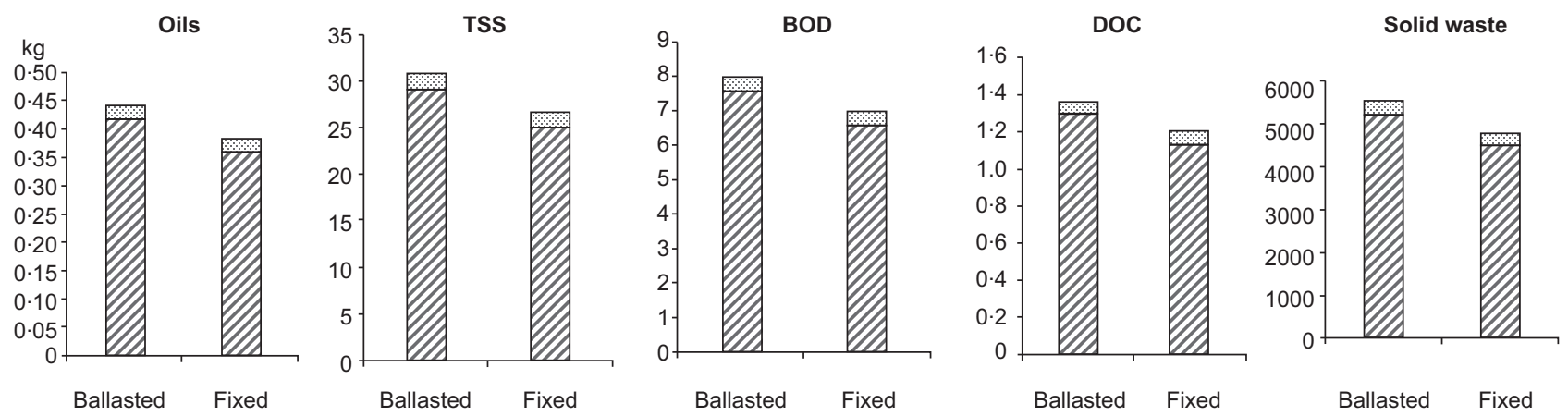

\footnotetext{
Raw material acquisition and material production

$\square$ Construction operations

End-of-life management
}

$\square$ Distribution

$\square$ Bridge in operation and maintenance activities

Figure 6. Life-cycle solid waste generation and emissions to the water for both ballasted and fixed track alternatives (in kilograms). $\mathrm{BOD}=$ biological oxygen demand; $\mathrm{DOC}=$ dissolved organic compounds; TSS $=$ total suspended solids 


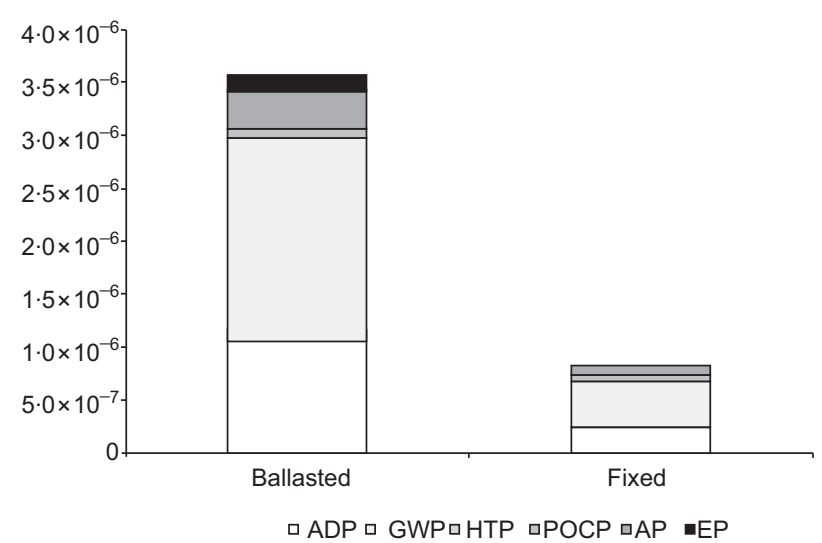

Figure 7. Normalised and weighted impacts for both ballasted and fixed track alternatives. $A D P=$ abiotic resource depletion; $A P=$ acidification; $\mathrm{EP}=$ eutrophication; GWP = climate change; HTP = human toxicity; POCP = photo-oxidant formation

sensitivity analysis is performed to test how the uncertain parameters affect the results.

In the bridge LCA analysis, the uncertainty parameter could be introduced from several sources - for example, the input data of material quantities, maintenance activities, transportation distance and end-of-life scenarios. In this paper, magnitudes of potential errors are assessed by studying the influence on the results of variations in input parameters of $10 \%$ at the inventory and impact assessment levels. Therefore, the resulting variations of the emissions to the air and water and the generation of solid wastes are compared with the original emissions.

For the ballasted case, the result shows that the largest variations occur for normal concrete, structural steel, diesel consumption and the duration of the replacement of the track system. Errors of $10 \%$ in the structural steel quantity affect the emissions of water pollutants and the generation of solid wastes by almost $10 \%$, and modify the emissions of carbon monoxide, sulfur dioxide, NMVOCs and PM10 by $7 \cdot 5 \%, 8 \cdot 4 \%$, $4 \cdot 4 \%$ and $7 \cdot 3 \%$, respectively. An error of $10 \%$ in the duration of the replacement of the tracks leads to substantial variations in the emissions of carbon dioxide $(7 \cdot 4 \%)$, methane $(9 \cdot 4 \%)$ and nitrogen oxides $(8 \cdot 8 \%)$, and of the energy demand $(6 \cdot 9 \%)$.

As for the fixed track case, structural steel is by far the most sensitive item. A $10 \%$ variation in structural steel input data affects the emissions by between $3 \cdot 5 \%$ and $9 \cdot 5 \%$, and the energy demand by $8 \%$.

At the impact assessment level, the resulting variations of the potential impact for each impact category are compared with

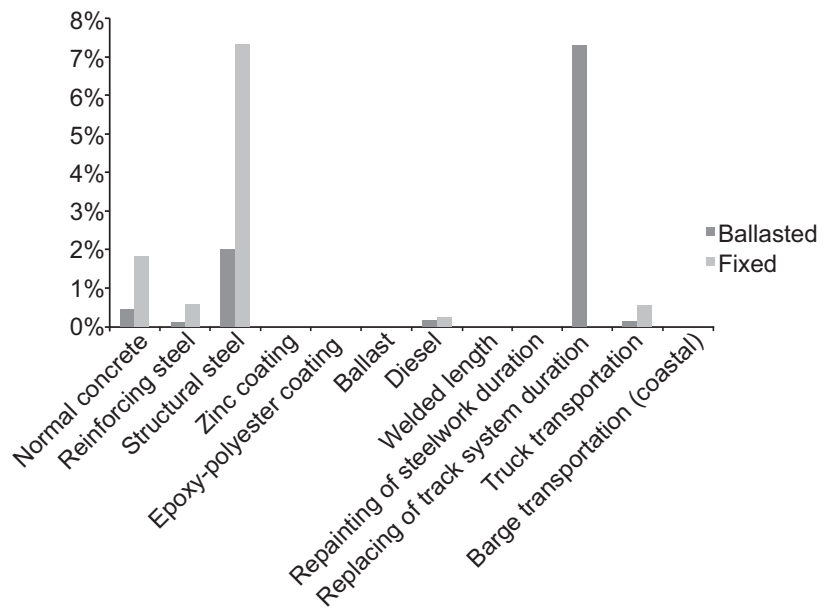

Figure 8. Results from sensitivity analysis, weighted results

the original impacts. Figure 8 shows the variation in the total weighted impact for each input parameter in both bridge design alternatives. Altering the input parameters by $10 \%$ does not affect the overall weighted impact more than $2 \%$, except for the structural steel in the fixed track case $(7 \cdot 2 \%)$ and the duration of the replacement of the track system in the ballasted track case $(7 \cdot 3 \%)$. These last items and the quantity of plain concrete should therefore be treated with a higher degree of accuracy, while rough estimations at $\pm 10 \%$ are enough for the other input parameters.

\section{Conclusion and discussion}

\subsection{Conclusion}

A simplified quantitative LCA approach has been implemented in order to compare the environmental performance of two railway bridge design alternatives. The simplification relied on omissions and assumptions that narrowed the scope of the analysis. The emphasis has been put on a limited set of air and water pollutants, which have been identified as relevant environmental indicators in the previous literature. Environmental data have been retrieved from the Ecoinvent v2.1 database (Ecoinvent, 2012), which provides average environmental data for Europe and Switzerland. The model accounted for all life-cycle stages, from raw material extraction to the final disposal of the construction materials at the end of the service life of the bridge.

The steel-concrete composite Banafjäl Bridge has been partly redesigned in Gillet (2010) to carry a single fixed concrete track. The two ballasted and fixed concrete track alternatives have been compared regarding their life-cycle emissions and potential impacts on the environment. The results showed that the environmental impact of the fixed track alternative has 
significant advantages in terms of each environmental impact category, when compared with the ballasted track alternative. From a sustainable development perspective, it would thus have been preferable to install a fixed track over the Banafjäl Bridge to reduce its overall impact on the environment by up to $77 \%$. The raw material phase has been found to be decisive in the life cycle in both alternatives. The frequency of the replacement of the track has been identified as a key environmental parameter, because the road traffic emissions during bridge closure nearly overwhelmed the other life-cycle stages.

A summary of the main study features is presented in Figure 9. The scale, from 0 to 2, represents the extent to which the model is streamlined; 0 refers to a more streamlined approach, while 2 refers to a less streamlined approach, 1 refers to an intermediate streamlined state. On one hand, the model accounts for all life-cycle stages; no qualitative but only quantitative data are used; all results are accessible and fully transparent, from disaggregated process data to normalised and weighted impacts; impacts are assessed at a local and global scale; and only a limited set of pollutants are considered. On the other hand, averages and generic data are used, and they are unspecific regarding time or location.

\subsection{Further research}

As highlighted above, no data have been found in the literature regarding the environmental burden of railway track maintenance and repair activities. Lee et al. (2008) estimated the amount of materials and energy to maintain the tracks at $1 \%$ of the initial construction stage material and energy demand. As the maintenance phase of a railway bridge has been found to be of the utmost importance in its life cycle especially when the closure to train traffic is required, it would be valuable to gather more accurate data about the maintenance operations features. In particular, track maintenance actions that involve the closure of the bridge need to be identified, together with their frequency, the equipment used, the amount of materials

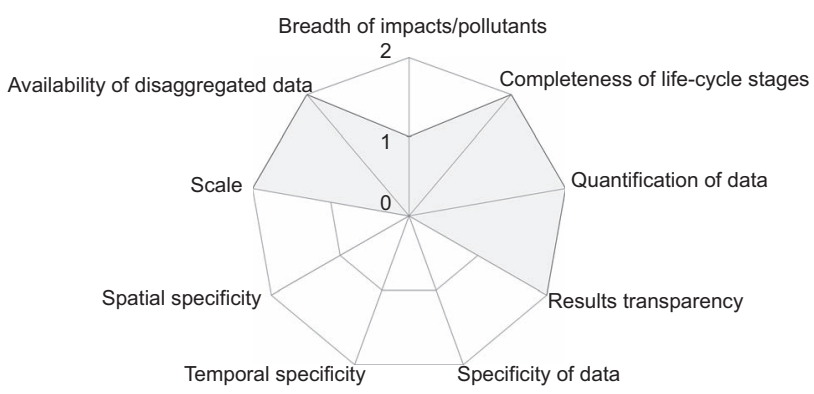

Figure 9. Summary of the main study features consumed and the proportion of the track that receives attention.

The Banafjäl Bridge is a single track railway bridge. When heavy maintenance is carried out, train traffic is temporarily halted. However, traffic can be operated on other tracks for bridges carrying many tracks. The environmental pressure of train traffic disturbance, such as partial traffic shift to the road, could be explored. In addition, the traffic at the end of the service life of the bridge is likely to be larger than that at the construction time. Traffic growth could then be included favourably in the model (Keoleian et al., 2005).

The model could also be modified to use environmental data specific to Scandinavia and Sweden, by changing the elementary process data in the Excel sheets. For instance, ready-mixed normal and high-performance concrete commonly used in Sweden, as well as transport services adapted to Swedish conditions, could serve as the basis for region-specific analysis. Similarly, Sweden-specific characterisation factors could be used instead of those calculated on a more global scale. For example, Finnveden and Nilsson (2005) developed site-specific characterisation factors for different parts of Sweden for air emissions of nitrogen oxides, sulfur oxides and particulates regarding ecosystem and human health impacts.

Missing data regarding nitrogen monoxide and nitrogen dioxide, ammonia and disaggregated NMVOC emissions could be included in the model to improve the accuracy of the results by combining data from other databases, like for example, the life-cycle inventory of Portland cement concrete from the Portland Cement Association for concrete manufacturing, or the Worldsteel life-cycle inventory for steel production.

Finally, it would be of the greatest interest to estimate the uncertainty of the environmental assessment results computed by the model presented. Considering the number of input parameters and their related uncertainty, a Monte Carlo method would be particularly useful. The model could then give the distribution of the inventory and impact results, based on the distribution of the amounts of inputs and outputs for each unit process.

\section{REFERENCES}

Banverket (2000) Arsta, Bro over Arstaviken StockholmSödertälje, km 3+800. Banverket, Sundyberg, Sweden, Uppspår. Reg. No. 854400-496-3 (in Swedish).

BEES (2009) http://www.nist.gov/el/economics/BEESSoftware. cfm) (accessed 04/04/2012).

Björklund L (2005) Dynamic analysis of a railway bridge subjected to high-speed trains. MSc thesis, Department of Civil and Architectural Structure Engineering, Division of 
Structural Design and Bridges, Royal Institute of Technology, Stockholm, Sweden.

Botniabanan AB (2010a) Environmental Product Declaration for railway track on the Bothnia line. Botniabanan $\mathrm{AB}$, Stockholm, Sweden, UN CPC 53212, Reg. no. S-P-00200. See http://gryphon.environdec.com/data/files/6/7222/ epd200.pdf (accessed 01/07/2012).

Botniabanan AB (2010b) Environmental Product Declaration for railway bridges on the Bothnia line. Botniabanan $\mathrm{AB}$, Stockholm, Sweden, UN CPC 53212, Reg. no. S-P-00199. See http://gryphon.environdec.com/data/files/6/7219/ epd199.pdf (accessed 01/07/2012).

Botniabanan AB (2010c) Environmental Product Declaration for freight transport on the Bothnia line. Botniabanan $\mathrm{AB}$, Stockholm, Sweden, UN CPC 6512, Reg. no. S-P-00195. See http://www.botniabanan.se/vitbokmiljo/dokument/ $5 \% 202 \% 209 \% 20$ EPD $\% 20$ for $\% 20$ freight $\%$ 20transport $\% 20$ on $\% 20$ the $\% 20$ Bothnia $\% 20$ Line.pdf (accessed 01/07/2012).

Brattebø H, Hammervold J and Reenaas M (2009) Environmental Effects - Life Cycle Assessment of bridges. ETSI Stage 2, Sub-project 2. Department of Hydraulic and Environmental Engineering, Norwegian University of Science and Technology, Norway.

Chester M and Horvath A (2009) Environmental assessment of passenger transportation should include infrastructure and supply chains. Environmental Research Letters 4(2), doi:10.1088/1748-9326/4/2/024008.

Classen M, Althaus HJ, Blaser S et al. (2009) Life Cycle Inventories of Metals. Final report Ecoinvent v2.1, No. 10. EMPA Dübendorf, Swiss Centre for Life Cycle Inventories, Dübendorf, Switzerland.

Doka G (2009) Life Cycle Inventories of Waste Treatment Services. Ecoinvent report, No. 13. Swiss Centre for Life Cycle Inventories, Dübendorf, Switzerland.

Ecoinvent (2012) http://www.ecoinvent.ch (accessed 04/04/2012). European Commission (2001) European Transport Policy 2010: time to decide. European Commission, Brussels, Belgium. See http:// ec.europa.eu/transport/strategies/doc/2001_white_paper/ 1b_com_2001_0370_en.pdf (accessed 01/10/2010).

Finnveden G and Nilsson M (2005) Site-dependent life-cycle impact assessment in Sweden. International Journal of Life Cycle Assessment 10(4): 235-239.

Gillet G (2010) Simply supported composite railway bridge: a comparison between ballasted and ballastless alternatives. MSc thesis, Department of Civil and Architectural Engineering, Division of Structural Design and Bridges, Royal Institute of Technology (KTH), Stockholm, Sweden.

Guinée JB, Gorrée M, Heijungs R et al. (2001) Life Cycle Assessment, an operational guide to the ISO standards. Ministry of Housing, Spatial Planning and the Environment (VROM) and Center of Environmental Science, Leiden University, Leiden, the Netherlands.
Horvath A and Hendrickson C (1998) Steel versus steelreinforced concrete bridges: environmental assessment. Journal of Infrastructure Systems 4(3): 111-117.

Kellenberger D, Althaus HJ, Künniger T et al. (2007) Life Cycle Inventories of Building products. Final Report Ecoinvent Data v2.0 No. 7. EMPA Dübendorf, Swiss Centre for Life Cycle Inventories, Dübendorf, Switzerland.

Keoleian GA, Kendall A, Dettling JE et al. (2005) Life cycle modeling of concrete bridge design: comparison of engineered cementitious composite link slabs and conventional steel expansion joints. Journal of Infrastructure Systems 11(1): 51-60.

Lee CK, Lee JY and Kim YK (2008) Comparison of environmental loads with rail track systems using simplified life cycle assessment (LCA). WIT Transactions on the Built Environment 101: 367-372.

Lorenz D, d'Amato M, Des Rosiers F et al. (2008) Sustainable Property Investment and Management: Key Issues and Major Challenges. RICS EU, Brussels, Belgium. See http:// www.joinricsineurope.eu/uploads/files/Sustainable $\% 20$ Property $\% 20$ Investment $\% 20$ and $\% 20$ management $\% 20$ RICS\%20sept \%2008.pdf (accessed 01/10/2010).

Lundmark T (2001) Bro over Banafjälsån. Konstruktionsberäkninbgar - Stål. ScandiaConsult Sverige AB, Luleå, Sweden (in Swedish).

Nyström P and Prokopov A (2010) Val av banöverbyggnad för höghastighetsspår - grov economisk kalkyl. RCON and Banverket, Sundyberg, Sweden (in Swedish).

Svensson N (2006) Life-Cycle Considerations for Environmental Management of the Swedish Railway Infrastructure. Dissertation no. 1064, Department of Mechanical Engineering, Linköping University, Sweden.

Vieira PS and Horvath A (2008) Assessing the end-of-life impacts of buildings. Environmental Science Technology 42(13): $4663-4669$.

\section{WHAT DO YOU THINK?}

To discuss this paper, please email up to 500 words to the editor at journals@ice.org.uk. Your contribution will be forwarded to the author(s) for a reply and, if considered appropriate by the editorial panel, will be published as discussion in a future issue of the journal.

Proceedings journals rely entirely on contributions sent in by civil engineering professionals, academics and students. Papers should be 2000-5000 words long (briefing papers should be $1000-2000$ words long), with adequate illustrations and references. You can submit your paper online via www.icevirtuallibrary.com/content/journals, where you will also find detailed author guidelines. 